\title{
Prospective, Randomized Un-Blinded Three Arm Controlled Study in Coronary Artery Revascularization with Minimal Invasive Extracorporeal Circulation Systems (MiECC): Surrogate Parameter Analysis of Biocompatibility
}

\author{
Arndt H. Kiessling, MD,${ }^{1}$ Harald Keller, CP, ${ }^{2}$ Anton Moritz, MD, ${ }^{2}$ \\ ${ }^{1}$ Medical School Berlin, Department of Clinical Research, Berlin; ${ }^{2}$ University Hospital, Department of Thoracic and Cardiovascular \\ Surgery, Frankfurt/Main, Germany
}

\section{ABSTRACT}

Objectives: Minimal extracorporeal circulation techniques and systems (MiECC) may reduce the negative side effects of conventional extracorporeal circulation (ECC). However, it is still unclear as to what this is caused by, the reduced priming volume and hemodilution, or the avoidance of blood-air contact and dispersion of mediastinal debris into the systemic circulation. The aim of the trial was the comparison of MiECC to an open ECC setup (openECC) or a system with reduced blood air and debris interaction (closeECC).

Methods: In a prospective randomized trial, 72 patients $(73 \pm 5.3$ years; $83 \%$ male) referred for coronary artery bypass graft $(\mathrm{CABG})$ were randomly assigned either to MiECC (priming volume $550 \mathrm{~mL}$ ), closeECC, or openECC (priming volume $1250 \mathrm{~mL}$ ). The laboratory surrogate endpoints (renal function, inflammatory response, ischemia, coagulation, and hemolysis) and clinical data were measured at six different time points (T1-6).

Results: Patients were comparable for all preoperative variables. The operation times (MiECC $261 \pm 79 \mathrm{~min}$; openECC $264 \pm 75 \mathrm{~min}$; closeECC $231 \pm 68 \mathrm{~min})$ and perfusion times (MiECC $115 \pm 49 \mathrm{~min}$; openECC353 $107 \pm 37 \mathrm{~min}$; closeECC $99 \pm 22 \mathrm{~min}$ ) revealed a trend of faster performance in the closeECC group $(P<.05)$. Pro-inflammatory cytokines, ischemia, and coagulation markers were significantly elevated postoperatively in all cardiopulmonary bypass types, and decreased to pre-baseline levels at discharge (T5) without identifiable statistical differences between the three study groups. Free-hemoglobin was not significantly increased by centrifugal pump or cell saver procedures. Significant intraoperative hemodilution effects due to the different priming volumes were demonstrated only at the end of operation (T2) $(\mathrm{MiECC} \mathrm{Hb} 9.6 \pm 1.1 \mathrm{~g} / \mathrm{dL}$; openECC Hb $9.0 \pm 0.8 \mathrm{~g} / \mathrm{dL}$; closeECC Hb $8.7 \pm 1 \mathrm{~g} / \mathrm{dL} ; P=.01)$.

Conclusion: Neither the hemodilution, suction technique (MiECC), nor blood-air interface (closeECC) could show sustainable benefits in this underpowered study, compared

Received November 30, 2017; accepted April 30, 2018.

Correspondence: Arndt-Holger Kiessling, Prof, Medical School Berlin, Department of Clinical Research, Calandrelli Strasse 1-9, D-12247 Berlin; +49-30-76-68-3753-33; fax: +49-30-76-68-37-53-69 (e-mail: cardiac.surgeon@dr-kiessling.com). to conventional ECC systems (openECC) in a high volume series of surrogate parameters.

\section{INTRODUCTION}

Since the invention in the 1950s, conventional cardiopulmonary bypass (CPB) has become essential in cardiac surgery [Gibbon 1994]. While the advantages of extracorporeal circulation (ECC) are obvious, such as a blood-free operative field, adverse effects such as activation of inflammation and coagulation pathways are also described [Borst 1999; Royston 1997]. In disastrous cases, these activations can trigger a systemic inflammatory response syndrome (SIRS) which can lead to an end-organ failure [Levy 2003; Laffey 2002; Royston 1997]. These cascades of systemic inflammation are caused by the secretion of a large number of mediators and the activation of certain natural defense mechanisms [Chai 2000].

Optimal perfusion techniques during coronary artery bypass surgery (CABG) remains a discussed field. Cardiopulmonary bypass (CPB), beating heart surgery (OPCAB) and minimal invasive extracorporeal circulation systems (MiECC) are the methods of choice. While the advantages of OPCABsurgery compared to $\mathrm{CPB}-\mathrm{CABG}$ are not convincing, the advantages of MiECC are described, especially a reduced inflammatory response [Vohra 2009; Khan 2004]. Remadi et al investigated 400 patients, and observed significantly higher C-reactive protein ( $\mathrm{CrP}$ ) levels in the $\mathrm{CPB}$-group compared to those treated with MiECC [Remadi 2006]. Through the less invasive characteristics of the MiECC system, such as the reduction of priming volume by the use of shorter lengths of tubes that are also heparin-coated, a reduction of systemic heparinization is possible. Priming volume and modified anticoagulation regime were responsible for the lower transfusion rates and higher postoperative hemocrit levels (hct) in MiECC patients [Anastasiadis 2016].

Due to the avoidance of blood-air contact through the elimination of the venous reservoir, the systemic inflammatory response should be reduced compared to $\mathrm{CPB}$. In the MiECC system, a centrifugal pump is used, and tube lengths are shortened so that less priming volume is used. Most often, neither cardiotomy suction (CS) nor venous reservoir is used. The blood has to be retransfused directly into the venous line. As an "intermediate" solution, the CS can be eliminated without complete absence of a venous reservoir. 


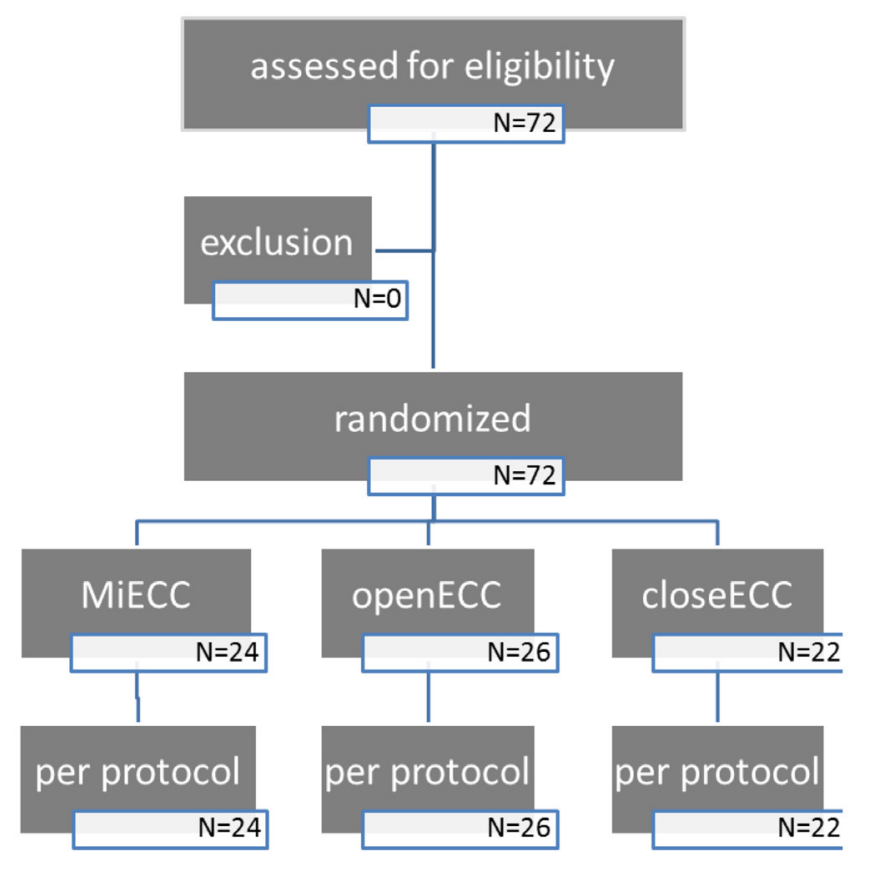

Figure 1. Randomization list.

There are several reports about the adverse effects of CS [Svitek 2010]. Its use is described to cause an amplification of the systemic inflammatory response and a resulting coagulopathy, as well as an exacerbation of the microembolic load and hemolysis. This can lead to a tendency towards increased blood loss, transfusion requirements, and organ dysfunction. El-Sabbagh et al examined fresh human blood in vitro and report that the inflammatory response and associated hemolysis during $\mathrm{CPB}$ may be related to air exposure, which could be reduced by minimizing the exposure of air to blood during CS [El-Sabbagh 2013]. Nakahira et al report that CS, but not open venous reservoirs, cause perioperative activation of coagulofibrinolysis, although they showed no influence on inflammatory response in their studies [Nakahira 2011]. Many modifications compared to maximal- or standard-CBP systems were not directly obvious in all published manuscripts about MiECC outcomes. In addition to the circuit's adaptations, the concomitant procedures (e.g. cardioplegia, anesthesia) were modified, and the beneficial aspects of MiECC may also be influenced by collateral techniques [Anastasiadis 2016].

The aim of the prospective, three-armed CABG trial design was the comparison of a closed MiECC system to a closed standard ECC (CloseECC) without CS, to an open standard system (OpenECC), to determine the blood-air interaction and MiECC effects on a series of surrogate laboratory markers (renal, inflammatory, myocardial, and coagulation parameters) by comparable concomitant procedures.

\section{METHODS}

\section{Patient Selection}

72 patients (age $73 \pm 5.3$ years; $81 \%$ male) were included in a prospective, randomized, three-armed, single center
Table 1. Patient Demographic Data and Preoperative Parameters Without any Significant Differences

\begin{tabular}{lccc}
\hline & $\begin{array}{c}\text { MiECC } \\
(n=24)\end{array}$ & $\begin{array}{c}\text { openECC } \\
(n=26)\end{array}$ & $\begin{array}{c}\text { closeECC } \\
(n=22)\end{array}$ \\
\hline NYHA>2 (\%) & 10.1 & 18.8 & 18.8 \\
Myocardial infarction (\%) & 13.0 & 7.2 & 8.7 \\
ASA class >2 (\%) & 29.0 & 31.9 & 26.1 \\
Ejection fraction <31 \% (\%) & 4.3 & 8.7 & 2.9 \\
Diabetes mellitus I/II (\%) & 11.6 & 14.5 & 13.0 \\
COPD & 1.4 & 4.3 & 4.3 \\
Age (years) & $72 \pm 5.2$ & $73 \pm 4.7$ & $73 \pm 5.9$ \\
Male (\%) & 790 & 96.0 & 72.0 \\
Weight (kg) & $82 \pm 12.8$ & $80 \pm 12.6$ & $85 \pm 14$ \\
\hline
\end{tabular}

NYHA indicates New York Heart Association; ASA, American Society of Anesthesiologists; COPD, chronic obstructive pulmonary disease; MiECC, minimal invasive extracorporeal circulation system; openECC, open extracorporeal circulation; closeECC, close extracorporeal circulation.

recruitment design. Patient demographic data and medical histories are summarized in Table 1 . Inclusion criteria were planned CABG-procedures with extracorporeal circulation support and age $>64$ years. Excluded were CABG-procedures in combination with operations on the carotid arteries, aorta, or valves. Patients who underwent a re-operation, had an acute myocardial infarction (ST-elevation myocardial infarction or Non ST-elevation myocardial infarction $<7$ days ago), had elevated serum creatinine levels $(>1.8 \mathrm{mg} / \mathrm{dL})$, had elevated liver enzymes (AST, ALT $>2 \mathrm{x}$ above norm), or had decreased hemoglobin $(\mathrm{Hb}<11 \mathrm{mg} / \mathrm{dL})$ were also excluded. Patients were divided into three subgroups with different extracorporeal circulation settings (Figure 1).

Blood samples were investigated before the start of ECC (T1), 60 minutes after ECC start (T2), four to six hours postoperative (T3), 24h postoperative (T4), and 48h postoperative (T5). Clinical outcome parameters were documented at discharge (T6) and at the 30-day follow up (T7). The study laboratories have been recognized according to DIN EN ISO 15189; DIN EN ISO 9001:2008 (accredited medical laboratories). Clinical parameters orient themselves according to the evaluations of the German Federal Multi-sector Quality Assurance (SQG, Aqua Institute Göttingen, Germany), and were extracted from existing postoperative databases.

\section{Anestbetic Management}

Anesthetic, operative, $\mathrm{CPB}$, and coagulation management were standardized. No changes in surgical, anesthetic, or perfusion techniques were made for the purpose of the study. On the day before the surgery, the patients were treated with 20 mg di-kaliumclorazepat (Tranxilium, Sanofi-Aventis GmbH, Hoechst, Germany) for premedication. General anesthesia was induced with 0.3 to $1 \mu \mathrm{g} / \mathrm{kg}$ sufentanil (Sufenta, JanssenCilag GmbH, Neuss, Germany), 1 to $2.5 \mathrm{mg} / \mathrm{kg}$ propofol 


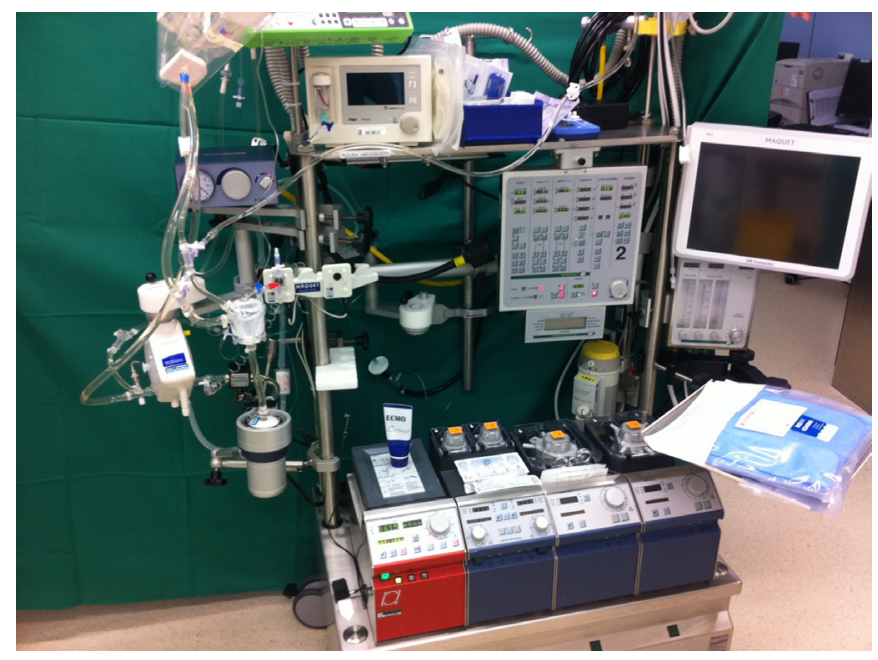

Figure 2. Setup of MiECC system (centrifugal pump, arterial filter, oxygenator and priming tubes) on a scaffold pole of a standard ECC (Jostra HL20, Hirrlingen, Germany).

(Disoprivan, AstraZeneca GmbH, Wedel, Germany), and 0.6 $\mathrm{mg} / \mathrm{kg}$ rocuronium (Esmeron, Essex GmbH, Munich, Germany). The maintenance of general anesthesia was achieved using 1 to 2 Vol\% sevoflurane (Sevoran, Abbott, Wiesbaden, Germany) and intermittent bole of sufentanil until the transfer to an intensive care unit. All patients were orally intubated and mechanically ventilated. Packed red blood cell concentrates were transfused to maintain a hematocrit greater than $18 \%$ during, and $25 \%$ after, $\mathrm{CPB}$.

\section{Extracorporeal Circulation Settings}

The conventional ECC bypass system drains venous deoxygenated blood, usually from a two stage cannula. The blood passes through a membrane oxygenator to become oxygenated, and blood is returned to the body usually via the aorta or subclavian artery through a roller pump. A heat exchanger controls the temperature of the blood infused back into the body. Because the drained blood from the venous cannula, $\mathrm{CS}$, or vents is applied into a central venous reservoir where it can freely mix with air, CPB is an "open system". Usually, the main difference in the MiECC-system compared to CPB is that in MiECC, the venous reservoir is eliminated. This generates a "fully closed" system with no blood-air contact. The disadvantage of this system is that blood from the operating field cannot be directly re-transfused via the system; there is no CS providing a fast blood transfer. Therefore, procedures with significant hemorrhage or open-heart procedures requiring the venting of blood are difficult to perform with MiECC.

In the MiECC system, centrifugal pumps are usually used. Through the pumps, a more physiologic circulation situation with less shear stress compared to roller pumps should be possible [Nakahira 2011]. In addition, through the MiECC system, a reduction in the priming volume is possible, due to the use of shorter lengths of tubing. The priming volume was reduced from $1290 \mathrm{~mL}$ in the openECC and closeECC to
Table 2. Setup of Three Different ECC Subgroups: MiECC, openECC, CloseECC

\begin{tabular}{lccc}
\hline & MiECC setup & $\begin{array}{c}\text { openECC } \\
\text { setup }\end{array}$ & $\begin{array}{c}\text { closeECC } \\
\text { setup }\end{array}$ \\
\hline Pump type & centrifugal & roller & roller \\
Blood air interaction & closed & open & closed \\
Cardiotomy reservoir & no & yes & yes \\
Sucker (blood try field) & cellsaver & ECC sucker & cellsaver \\
Vent & yes & yes & yes \\
Oxygenator & Quadrox & Quadrox & Quadrox \\
Arterial filter & yes & yes & yes \\
Priming volume & $600 \mathrm{~mL}$ & $1290 \mathrm{~mL}$ & $1290 \mathrm{~mL}$ \\
Cardioplegia & Calafiore & cold blood & cold blood \\
ACT target & $>350 \mathrm{sec}$ & $>450 \mathrm{sec}$ & $>450 \mathrm{sec}$ \\
\hline
\end{tabular}

MiECC indicates minimal invasive extracorporeal circulation system; openECC, open extracorporeal circulation; closeECC, close extracorporeal circulation; ECC, extracorporeal circulation; ACT, activated clotting time.

$600 \mathrm{~mL}$ in the MiECC group. Shorter tubing reduces the surface area for blood to interact with, which could also reduce the inflammatory response. The heparinization of patients compared to $\mathrm{CPB}$ can also be reduced. QuadroX- i system (Maquet, Hirrlingen, Germany) membrane oxygenators were used in all three subgroups. The tubes were coated with an adult Softline coating (Maquet, Hirrlingen, Germany) in closeECC and openECC groups, and adult Bioline coating (Maquet, Hirrlingen, Germany) in the MiECC group. The activated clotting time (ACT) could be reduced from $>450 \mathrm{sec}$ in the two open/closeECC groups compared to $350-400 \mathrm{sec}$ in the MiECC group (table 2).

In the closeECC group, only a cell-saver sucker was used, with a flexible venous reservoir to avoid debris and blood-air interaction. Priming volume and heparinization were equal to openECC. During CPB, non-pulsatile flow was maintained at $2.6-3 \mathrm{~L} / \mathrm{min} / \mathrm{m}^{2}$, and mean arterial blood pressure was maintained at $50-70 \mathrm{mmHg}$ by the addition of norepinephrine (Arterenol®, Sanofi-Aventis GmbH, Hoechst, Germany). Extracorporeal circulation was performed under mild hypothermia $\left(32^{\circ} \mathrm{C}\right)$. On completion of surgery, the patients were warmed and weaned from $\mathrm{CPB}$. To reverse the anticoagulant effects of heparin, protamine sulfate (Protaminsulfat, Novo Nordisk Pharma GmbH, Vienna, Austria) was administered, guided by the activated clotting time.

\section{Statistical Analyses}

Continuous variables were expressed as means with standard deviation. Categorical variables were expressed as frequencies. The median was calculated, in addition to the arithmetic mean value and standard deviation. All data were tested for normality. Calculations were performed with the Anova-, Scheffe-, and Kruskal Wallis tests. The criteria for rejection 
Table 3. Mean Values of 28 Different Parameters at Five Collection Times in Three Different ECC Subgroups.

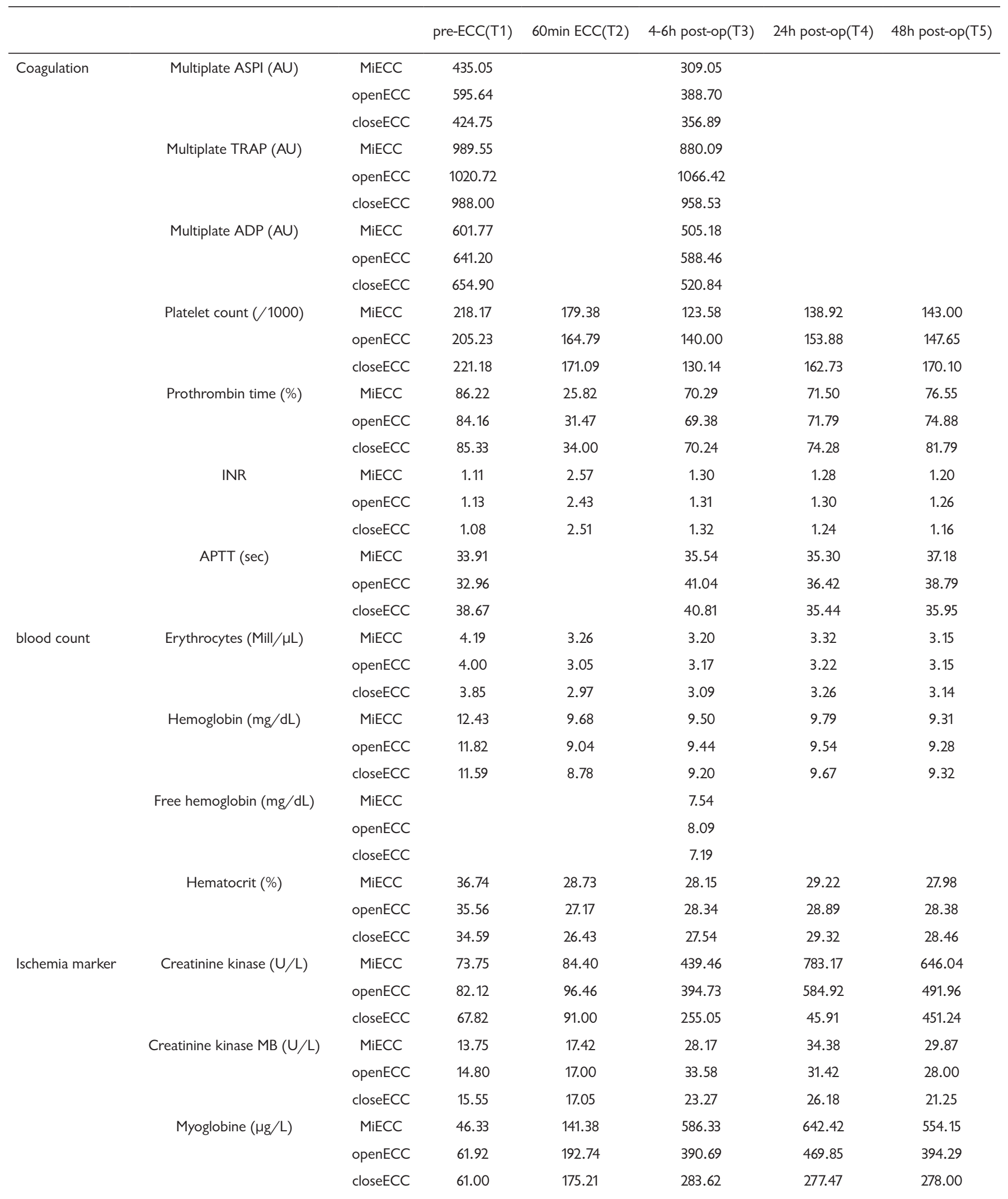




\begin{tabular}{|c|c|c|c|c|c|c|c|}
\hline \multirow{3}{*}{\multicolumn{2}{|c|}{ Troponine $\mathrm{T}(\mu \mathrm{g} / \mathrm{L})$}} & MiECC & 22.97 & 62.54 & 477.13 & 469.32 & 522.45 \\
\hline & & openECC & 26.92 & 70.10 & 378.67 & 273.99 & 295.44 \\
\hline & & closeECC & 22.35 & 83.61 & 448.52 & 284.74 & 223.51 \\
\hline \multirow{3}{*}{\multicolumn{2}{|c|}{$\gamma$-Glutamyltransferase $(\mathrm{U} / \mathrm{L})$}} & MiECC & 30.00 & 21.13 & 11.80 & 24.09 & 35.60 \\
\hline & & openECC & 53.73 & 38.61 & 30.27 & 22.43 & 21.86 \\
\hline & & closeECC & 24.95 & 19.20 & 25.38 & 28.30 & 32.20 \\
\hline \multirow{3}{*}{\multicolumn{2}{|c|}{ Aspartate aminotransferase $(\mathrm{U} / \mathrm{L})$}} & MiECC & 19.91 & 18.50 & 33.46 & 53.86 & 58.25 \\
\hline & & openECC & 25.04 & 21.79 & 36.56 & 44.65 & 41.10 \\
\hline & & closeECC & 26.15 & 24.60 & 36.60 & 41.17 & 38.00 \\
\hline \multirow{3}{*}{\multicolumn{2}{|c|}{ Alanine aminotransferase $(\mathrm{U} / \mathrm{L})$}} & MiECC & 19.95 & 16.27 & 16.75 & 19.88 & 23.04 \\
\hline & & openECC & 26.54 & 18.45 & 20.38 & 25.00 & 22.39 \\
\hline & & closeECC & 24.30 & 18.80 & 29.77 & 28.00 & 26.67 \\
\hline \multirow{3}{*}{\multicolumn{2}{|c|}{ Creatinine $(\mathrm{mg} / \mathrm{dL})$}} & MiECC & 0.87 & 0.80 & 0.82 & 0.96 & 1.16 \\
\hline & & openECC & 0.88 & 0.84 & 0.91 & 1.07 & 1.39 \\
\hline & & closeECC & 0.84 & 0.77 & 0.82 & 0.96 & 1.12 \\
\hline \multirow{3}{*}{\multicolumn{2}{|c|}{ Lactate dehydrogenase $(\mathrm{U} / \mathrm{L})$}} & MiECC & 163.70 & 135.90 & 166.04 & 225.72 & 242.21 \\
\hline & & openECC & 174.28 & 153.57 & 225.16 & 223.78 & 237.09 \\
\hline & & closeECC & 183.36 & 139.50 & 179.43 & 215.24 & 225.55 \\
\hline \multirow{3}{*}{\multicolumn{2}{|c|}{ Bilirubin (mg/dL) }} & MiECC & 0.68 & 0.60 & 0.74 & 0.70 & 0.67 \\
\hline & & openECC & 0.74 & 0.61 & 0.87 & 0.81 & 0.67 \\
\hline & & closeECC & 0.62 & 0.58 & 0.66 & 0.70 & 0.53 \\
\hline \multirow[t]{21}{*}{ Inflammation } & Interleucin 6 (ng/L) & MiECC & 3.49 & 17.13 & 484.13 & 233.18 & 166.66 \\
\hline & & openECC & 3.49 & 25.94 & 310.85 & 209.09 & 134.49 \\
\hline & & closeECC & 7.73 & 16.19 & 362.66 & 230.02 & 214.19 \\
\hline & Interleucin $10(\mathrm{pg} / \mathrm{L})$ & MiECC & 0.16 & 2.35 & 3.69 & 2.07 & 3.58 \\
\hline & & openECC & 0.28 & 7.97 & 2.58 & 1.80 & 0.89 \\
\hline & & closeECC & 0.27 & 10.89 & 2.70 & 1.70 & 1.71 \\
\hline & PMNelastase (ng/L) & MiECC & 52.38 & 420.26 & 118.26 & 84.65 & 107.22 \\
\hline & & openECC & 42.38 & 403.46 & 183.96 & 91.43 & 103.48 \\
\hline & & closeECC & 43.17 & 412.16 & 146.48 & 83.69 & 92.16 \\
\hline & TNF-alpha (pg/L) & MiECC & 3.13 & 3.00 & 3.76 & 3.58 & 3.56 \\
\hline & & openECC & 3.18 & 3.66 & 4.05 & 3.12 & 3.63 \\
\hline & & closeECC & 3.66 & 4.60 & 4.88 & 3.74 & 4.48 \\
\hline & Leucocytes ( $/ \mathrm{nL})$ & MiECC & 6.49 & 7.24 & 11.39 & 12.29 & 11.92 \\
\hline & & openECC & 6.79 & 9.17 & 10.91 & 11.54 & 12.20 \\
\hline & & closeECC & 6.49 & 7.69 & 8.76 & 10.83 & 11.57 \\
\hline & Procalcitonin $(\mu \mathrm{g} / \mathrm{l})$ & MiECC & 0.07 & 0.05 & 0.21 & 0.75 & 1.11 \\
\hline & & openECC & 0.04 & 0.03 & 0.35 & 0.90 & 1.05 \\
\hline & & closeECC & 0.06 & 0.03 & 0.49 & 0.59 & 1.19 \\
\hline & Fibrinogen $(\mathrm{mg} / \mathrm{dL})$ & MiECC & 310.83 & 183.29 & 196.21 & 359.65 & 553.00 \\
\hline & & openECC & 323.52 & 211.19 & 232.71 & 342.94 & 560.00 \\
\hline & & closeECC & 323.32 & 227.80 & 212.62 & 388.08 & 556.27 \\
\hline
\end{tabular}

Significant results are marked in grey blocks $(P<.05)$.

MiECC indicates minimal invasive extracorporeal circulation system; openECC, open extracorporeal circulation; closeECC, close extracorporeal circulation; ECC, extracorporeal circulation system; ASPI, arachidonic acid; AU, aggregation units; ADP, adenosine phosphate; INR, international normalized ratio; APTT, activated partial thromboplastin time. 
Table 4. Clinical Outcome Parameters Without any Significant Differences at Discharge and in the 30-Day Follow Up.

\begin{tabular}{lccc}
\hline & $\begin{array}{c}\text { MiECC } \\
(\mathrm{n}=24)\end{array}$ & $\begin{array}{c}\text { openECC } \\
(\mathrm{n}=26)\end{array}$ & $\begin{array}{c}\text { closeECC } \\
(\mathrm{n}=22)\end{array}$ \\
\hline Sternal infection ( $\mathrm{n})$ & 0 & 0 & 0 \\
Low cardiac output & 2 & 0 & 0 \\
Re-thoracotomy & 2 & 0 & 0 \\
Respiratory decompensation & 2 & 0 & 1 \\
Psychosyndrome & 3 & 1 & 1 \\
Renal insufficiency & 2 & 0 & 1 \\
Atrial fibrillation & 1 & 4 & 2 \\
30 day mortality & 1 & 0 & 0 \\
Hospital stay & $12 \pm 7$ & $12 \pm 4$ & $12 \pm 4$ \\
ICU stay (d) & $2.2 \pm 2$ & $2 \pm 2$ & $2 \pm 2$ \\
Red blood cells transfusion (ml) & 500 & 520 & 563 \\
Operation time (min) & $261 \pm 79$ & $264 \pm 75$ & $231 \pm 68$ \\
Perfusion time (min) & $115 \pm 49$ & $107 \pm 37$ & $99 \pm 22$ \\
\hline
\end{tabular}

MiECC indicates minimal invasive extracorporeal circulation system; openECC, open extracorporeal circulation; closeECC, close extracorporeal circulation; ICU, intensive care unit.

of the zero hypothesis was $P<.05$. Power $(0.8)$ and alpha $(0.05)$ were calculated for the primary endpoint "transfusion rate," based on the publication of Anastasiadis et al [Anastasiadis 2016]. Simple randomization (ratio 1:1:1) and statistics were calculated with SPSS 22.0 (IBM, Armonk, USA). Conduction of the trial was approved by the Ethics Committee of the Johann Wolfgang Goethe University, Frankfurt am Main, Germany (E23/11). Patients were informed about the contents of the study and gave their consent to participate with their signature. The study was registered in a public trail register (NCT01306903) (Figure 1).

\section{RESULTS}

\section{Inflammation}

All three subgroups contained similar demographic patient data, as shown in Table 1. Other than the results for IL10 and PMN elastase, there was no significant difference between inflammation markers from T1-T5. IL10 showed a significant preoperative difference, which remained in the first 60 minutes of extracorporeal circulation but disappeared in further measurements. PMN elastase showed a significant difference 60 minutes after extracorporeal circulation, but no statistical difference remained after four to six hours. The observed inflammatory response difference between the groups disappeared in the postoperative period. Four to six hours after ECC initiation there remained no significant difference between minimal invasive and open or closed extracorporeal circulation in inflammatory response. Beside PMN elastase and IL6, the remaining measured proinflammatory cytokines showed no significant difference. Procalcitonine, interleucin 6 and Tumor Necrosis Factor Alpha were similar in endpoints T1-T5 in all three groups. Intraoperatively, a slight reduction of operation time in the closeECC Group (MIECC $261 \pm 79 \mathrm{~min}$; openECC $264 \pm 75 \mathrm{~min}$; closeECC $231 \pm 68 \mathrm{~min}$ ) as well as reduced perfusion time (MIECC $115 \pm$ $49 \mathrm{~min}$; openECC $107 \pm 37 \mathrm{~min}$; closeECC $99 \pm 22 \mathrm{~min}$ ) with $P>.05$ could be seen. (Table 3 ). Clinical signs of a systemic inflammatory syndrome could not be observed.

\section{Coagulation/Hemolysis}

Platelet function was not influenced by the different ECC systems. Multiplate analysis four to six hours postoperative (T3) were not significantly different. The activated partial thromboplastin time (aPTT) in this analysis period (T3) was the only parameter with a $P$ value $<.05$ with lower results in the MiECC group. Effects by different pump types in the groups could also not observed. The free hemoglobin was similar at T3 for all ECC groups. (Table 3)

\section{Ischemic Parameter}

Liver (ALT;AST, bilirubin, LDH, $\gamma$-GT), kidney (creatinine), and cardiac (Trop.T, CK, CKMB) surrogate markers could not show that one of the ECC systems was beneficial for the patients outcome. From the preoperative (T1) to the $48 \mathrm{~h}$ postoperative (T5) period, an increase in all parameters could be observed, but without any significant differences in the ECC groups. The only exceptions is LDH at T3, with higher values in the openECC group (225U/L) compared to MiECC (166U/l).

\section{Clinical Outcome}

Within the 30 days of postoperative observation, one patient in the MiECC group died on fourth postoperative day because of multiorgan failure, in the closeECC and openECC group, all patients were alive. Mean ICU stay was $2 \pm 1$ days, mean hospital stay was $12 \pm 6$ days, with no significant difference between the three subgroups. There was no myocardial infarction or case of sepsis in any subgroup. There were two low cardiac output syndromes in the MiECC group; atrial fibrillation occurred in all three groups without significant differences but with a lower trend in the MiECC group. Two patients in the MiECC group and one patient in the closeECC group had to undergo renal replacement therapy. (Table 4)

\section{DISCUSSION}

In a prospective, randomized, multi-center study with 500 patients, El-Essawi et al showed a benefit in clinical outcome in the minimized extracorporeal circulation group, with a lower inflammation response [El-Essawi 2011]. In 2005, Abdel Rahman et al investigated a CorX system (CardioVention Inc., Santa Clara, CA, USA) [Abdel-Rahman 2005]. It was designed as a closed circuit without an additional suction line and venous reservoir, with less heparin coating and a different de-airing management compared to MiECC. In 204 patients, they observed a lower inflammatory response in 
the minimal invasive system compared to conventional ECC. Extracorporeal circulation allows a safe and often complete revascularization in coronary artery bypass surgery. If we exclude patients who can potentially be revascularized without extracorporeal circulation, the optimal perfusion strategy for the remaining patients is a controversial discussion even if there are groups reporting of advantages of MiECC versus OPCAB revascularization [Formica 2013].

Reviews and meta-analysis of the simplification of the conventional ECC system to MiECC describe an advantage of MiECC in the form of a reduced priming volume, reduced blood transfusion requirements, and reduction activation of inflammatory parameters and need for blood transfusion [Anastasiadis 2016; Fromes 2002]. In addition to these effects, MiECC allows an elimination of blood-air contact, which appears to have a positive effect on postoperative clinical outcome [Koch 2006a; Koch 2006b]. We investigated the inflammatory response in 72 patients, with three different extracorporeal circulation settings. In addition to the openECC and MiECC groups, we had a closeECC group, which had settings similar to openECC but with a reduced blood-air interaction due to the elimination of CS.

Although preoperative patient data was similar, no persistent significant reduction of inflammation data in the MiECC group was observed. The inflammatory markers were very well elevated in the first 60 minutes to three hours of extracorporeal circulation in the ECC Group, but in the remaining operation time, the three groups approximated to each other: the initial significant advantage disappeared after three hours. The clinical outcome with immediate postoperative events and the 30 days survival showed no benefits in the MiECC group. It is evident that the investigated patient collective with 72 patients in total is quite small, but the postoperative data is still surprising, considering that studies with a lower patient collective showed an advantage of using MiECC [Farneti 2008; Van Boven 2005].

However, some other groups could not show a general benefit of MiECC either. Beghi et al investigated 60 patients in a prospective study to show a lower hemolysis, interleukin-6 cytokine, and plasma C-reactive protein release in the MiECC group compared to conventional ECC, but could not demonstrate a clearly significant superiority of the MiECC system [Beghi 2006]. Mazzei et al showed a similar release of inflammatory markers for MiECC and off-pump at all endpoint times [Mazzei 2007]. Formica et al investigated 61 patients and showed similar clinical outcomes on MiECC, ECC, and OPCAB groups with similar inflammatory response except in TNF alpha, which was raised in the ECC group [Formica 2013].

A partially reduced inflammatory response could be shown in the MiECC group in the early postoperative period. Four to six hours postoperatively, however, there were no significant differences in inflammatory parameters. The advantage of an early postoperatively reduced inflammatory response may not be apparent in a collective of 72 patients. To discuss if other inflammatory parameters would lead to a more significant a statement, we focused on the most commonly used in literature.
A benefit of the elimination of CS in the closeECC group compared to the MiECC and openECC groups cannot demonstrated. However this advantage is widely accepted in literature, and could be obscured through an underpowered patient collective in this series. Additionally, the advantages of minimal invasive circuits may be obscured once these systems are not used as a daily routine. Finally, we compared MiECC group to low prime volume openECC systems with $1250 \mathrm{ml}$ priming volume. While the CABG surgery patient collective becomes older and morbidity is rising, we should take every possibility to reduce side effects. Further investigations with a larger patient collective will be necessary to find the right answers for optimal perfusion strategy during aortocoronary revascularization. The evidence for hard endpoints (mortality) is still under discussion for MiECC systems [Anastasiadis 2016].

\section{ACKNOWLEDGEMENT}

The authors would like to express their particular thanks to the Study Coordinator Mrs. Sonja Friese for data acquisition, logistics, and data management, and to the perfusionists of Maquet Services.

\section{REFERENCES}

Abdel-Rahman U, Ozaslan F, Risteski PS, et.al. 2005. Initial experience with a minimal invasice extracorporeal bypass system: is there a clinical benefit? Ann Thorac Surg 80:238-43.

Anastasiadis K, Murkin J, Antonitsis P, et al. 2016. Use of minimal invasive extracorporeal circulation in cardiac surgery: principles, definitions and potential benefits. A position paper from the Minimal invasive ExtraCorporeal Technologies international Society (MiECTiS). Interact Cardiovasc Thorac Surg 22:647-62.

Beghi C, Nicolini F, Agostinelli A, et al. 2006. Mini-cardiopulmonary bypass system: results of a prospective randomized study. Ann Thorac Surg 81:1396-400.

Borst C, Gründeman PF. 1999. Minimally invasive coronary artery bypass grafting: an experimental perspective. Circulation 99:1400-3.

Chai PJ, Nassar R, Oakeley AE, et al. 2000. Soluble complement receptor-1 protects heart, lung, and cardiac myofilament function from cardiopulmonary bypass damage. Circulation 101:541-6.

El-Essawi A, Hajek T, Skorpil J, et al. 2011. Are minimal invasive perfusion circuits the better heart lung machines? Final results of a prospective randomized multicentre study. Perfusion 26:470-8.

El-Sabbagh AM, Toomasian CJ, Toomasian JM, et al. 2013. Effect of air exposure and suction on blood cell activation and hemolysis in an in vitro cardiotomy suction model. ASAIO J 59:474-9.

Farneti PA, Sbrana S, Spiller D, et al. 2008. Reduction of blood coagulation and monocyte-platelet interaction following the use of a minimal extracorporeal circulation system (Synergy) in coronary artery bypass grafting (CABG). Perfusion 23:49-56.

Formica F, Mariani S, Broccolo F, et al. 2013. Systemic and myocardial inflammatory response in coronary artery bypass graft surgery with miniaturized extracorporeal circulation: differences with a standard circuit and off-pump technique in a randomized clinical trial. ASAIOJ 59:600-6.

Fromes Y, Gaillard D, Ponzio O, et al. 2002. Reduction of the inflammatory response following coronary bypass grafting with total minimal 
extracorporeal circulation. Eur J Cardiothorac Surg 22:527-33.

Gibbon JH Jr. 1994. Application of a mechanical heart and lung apparatus to cardiac surgery. Minn Med 37:171-85.

Khan NE, De Souza A, Mister R, et al. 2004. A randomized comparison of off-pump and on-pump multivessel coronary-artery bypass surgery. $\mathrm{N}$ Engl J Med 350:21-8.

Koch CG, Khandwala F, Li L, et al. 2006. Persistent effect of red cell transfusion on health-related quality of life after cardiac surgery. Ann Thorac Surg 82:13-20.

Koch CG, Li L, Duncan AI, et al. 2006. Transfusion in coronary artery bypass grafting is associated with reduced long-term survival. Ann Thorac Surg 81:1650-7.

Laffey JG, Boylan JF, Cheng DC. 2002. The systemic inflammatory response to cardiac surgery: implications for the anesthesiologist. Anesthesiology. 97:215-52.J.

Levy JH, Tanaka KA. 2003. Inflammatory response to cardiopulmonary bypass. Ann Thorac Surg 75:S715-20.

Mazzei V, Nasso G, Salamone G, et al. 2007. Prospective randomized comparison of coronary bypass grafting with minimal extracorporeal circulation system (MIECC) versus off-pump coronary surgery. Circulation 116:1761-7.
Nakahira A, Sasaki Y, Hirai H, et al. 2011. Cardiotomy suction, but not open venous reservoirs, activates coagulofibrinolysis in coronary artery surgery. J Thorac Cardiovasc Surg 141:1289-97.

Remadi JP, Rakotoarivelo Z, Marticho P, et al. 2006. Prospective randomized study comparing coronary artery bypass grafting with the new mini-extracorporeal circulation Jostra System or with a standard cardiopulmonary bypass. Am Heart J 151:198.

Royston D. 1997. The inflammatory response and extracorporeal circulation. J Cardiothorac Vasc Anesth. 11:341-54.

Svitek V, Lonsky V, Anjum F. 2010. Pathophysiological aspects of cardiotomy suction usage. Perfusion 25:147-52.

Van Boven WJ, Gerritsen WB, Zanen P, et al. 2005. Pneumoproteins as a lung-specific biomarker of alveolar permeability in conventional onpump coronary artery bypass graft surgery vs mini-extracorporeal circuit: a pilot study. Chest 127:1190-5.

Vohra HA, Whistance R, Modi A, et al. 2009. The inflammatory response to miniaturised extracorporeal circulation: a review of the literature. Mediators Inflamm 2009:707042.

Wheeldon DR, Bethune DW, Gill RD. 1990. Vortex pumping for routine cardiac surgery: a comparative study. Perfusion 5:135-43. 